\title{
Improving student learning outcomes in science subjects through a multiple intelligence approach
}

\author{
Wafiroh \\ SD Negeri Prapag Lor 02 \\ wafiroh45@gmail.com
}

\section{Article History}

received 3/12/2020

\begin{abstract}
The purpose of this study is to improve student learning outcomes in science subjects in fifth grade elementary school using the multiple intelligence approach. The research conducted is Classroom Action Research (CAR). for two cycles. Stages of each the cycle is planning, implementation, observation and reflection. Based on the results of research conducted using the multiple intelligence approach, it shows maximum results and students learn to be more effective, enthusiastic and fun at each meeting. because student learning outcomes are marked by the results of research detailed from the initial data, they get a complete score above the $K K M 70$ with a percentage of $30 \%$ and incompletely reach a value below the KKM 70 with a percentage of $70 \%$ while in the first cycle, the complete score above the KKM 70 reached a percentage of $50 \%$ and the incomplete score below the KKM 70 score got a $50 \%$ percentage and the second cycle got a complete score above the KKM 70, which was $90 \%$ while the incomplete score reached the KKM 70 that is $10 \%$. These results indicate that using a multiple intelligence approach can improve student learning outcomes especially in science subjects at SD Negeri Prapag Lor 02
\end{abstract}

Keywords: learning outcomes, multiple intellegence, science

\begin{abstract}
Abstrak
Tujuan dari penelitian ini adalah untuk meningkatkan hasil belajar peserta didik pada mata pelajaran IPA di sekolah dasar kelas $\mathrm{V}$ dengan gunakan pendekatan multiple intellegence. Penelitian yang dilakukan adalah Penelitian Tindakan Kelas (PTK) sebanyak dua siklus. Tahapan setiap siklusnya adalah perencanaan, pelaksanaan, observasi dan refleksi. Berdasarkan hasil penelitian yang dilakukan dengan menggunakan pendekatan multiple intellegence ini menunjukkan hasil yang maksimal dan siswa dalam pembelajarannya lebih efektif, semangat dan menyenangkan pada setiap pertemuannya. karena Hasil belajar siswa ditandai dengan hasil penelitian yang dirinci dari data awal mendapat nilai yang tuntas mencapai nilai diatas KKM 70 dengan prosentasi yaitu 30\% dan tidak tuntas mencapai nilai dibawah KKM 70 dengan prosentasi $70 \%$. sedangkan pada siklus I mendapat nilai yang tuntas diatas KKM 70 mencapai prosentasi yaitu 50\% dan tidak tuntas di bawah nilai KKM 70 mendapat prosentasi $50 \%$ dan siklus II mendapat nilai yang tuntas diatas KKM 70 yaitu $90 \%$ sedangkan nilai yang tidak tuntas mencapai nilai KKM 70 yaitu $10 \%$. Hasil ini menunjukan bahwa dengan menggunakan pendekatan multiple intellegence dapat meningkatkan hasil belajar peserta didik khususnya pada mata pelajaran IPA di SD Negeri Prapag Lor 02
\end{abstract}

Kata kunci: hasil belajar, multiple intellegence, IPA

Social, Humanities, and Education Studies (SHEs): Conference Series https://jurnal.uns.ac.id/shes

p-ISSN 2620-9284

e-ISSN 2620-9292 


\section{PENDAHULUAN}

Pendidikan di Sekolah Dasar merupakan langkah awal dalam memproses dan mengembangkan kemampuan yang paling mendasar bagi setiap siswa, dimana tiaptiap siswa harus belajar secara aktif karena adanya dorongan dalam diri dan adanya suasana yang memberikan kemudahan bagi perkembangan dirinya secara optimal (Agus Taufiq, 2018: 1.9)

Pendidikan di Sekolah Dasar bukan hanya diorientasikan pada memberi bekal kemampuan membaca, menulis dan berhitung, melainkan menyiapkan intelektual, sosial, dan personal siswa secara optimal untuk belajar secara aktif mengembangkan dirinya sebagai pribadi, sebagai anggota masyarakat, sebagai warga negara, dan sebagai makhluk Tuhan Yang Maha Esa (Agus Taufiq, 2018: 1.9)

Kecerdasan merupakan kemampuan untuk memecahkan masalah atau membuat produk yang dihargai di lingkungan kebudayaan. Kecerdasan merupakan kemampuan utama untuk menalar, merencanakan masalah, berfikir, memahami gagasan, menggunakan bahasa dan belajar.

Namun Selama ini, yang dianggap kecerdasan adalah melulu kecerdasan bahasa dan kecerdasan logika (matematika), sedangkan yang lain dianggap tidak atau sekurang-kurangnya "tidak berhubungan langsung" dengan masalah kecerdasan. Menurut pakar psikologi howard garder dalam modul belajar dan pembelajaran ( Hanikah, 2013: 60 ) bahwa proses pembelajaran atau lebih dikenal dengan sebutan kata "mendidik" erat kaitannya dengan semua elemen syaraf dan potensi yang ada di dalam jiwa anak tersebut. Karena, hakikat dari tujuan pembelajaran adalah menumbuhkan semangat anak didik agar berkembang potensinya secara utuh.

Konsep dasar multiple intelligence. Ungkapan Howard Gardner pada tahun 1983 dalam bukunya Frames of Mind yang berbunyi our culture defined intelligence too narrowly merupakan dasar pemikiran munculnya teori multiple intelligence. la memandang bahwa ruang lingkup potensi manusia melebihi skor IQ dan tidak terbatas hanya pada kemampuan memecahkan masalah dan menghasilkan produk. Karena Bagi gardner tidak ada anak yang bodoh atau pintar, yang ada hanya anak menojol dalam salah satu beberapa jenis dalam kecerdasan. (Hera Lestari Mikarsa, 2018: 7.26)

Gardner ( Armstrong, 1994) dalam buku Pendidikan anak di SD ( Agus Taufik, 2018: 6.20) telah melakukan pemetaan kemampuan manusia ke dalam tujuh kategori kecerdasan yang lebih komprehensif yaitu :Menurut teori multiple intelligence, bahwa setiap anak memiliki aneka ragam kecerdasan yaitu kecerdasan bahasa (linguistik), kecerdasan logika matematika, kecerdasan visual-spasial, kecerdasan musikal, kecerdasan kinestetik tubuh, kecerdasan interpersonal (sosial), kecerdasan intrapersonal dan kecerdasan naturalis.

IImu pengetahuan alam adalah ilmu yang mempelajari tentang gejala-gejala alam yang dapat dirumuskan kebenarannya secara empiris.

Ruang lingup kajian IPA di SD secara umum meliputi dua aspek yaitu kajian ilmiah dan pemahaman konsep. Lingkup kerja ilmiah meliputi kegiatan menyelidikan, berkomunikasi ilmiah, pengembangan kreativitas, pemecahan masalah, sikap, dan nilai ilmiah. Lingkup pemahaan konsep dalam kurikulum KTSP relatif sama jika dibandingkan dengan kurikulum berbasis kompetensi (KBK) yang sebelumnya digunakan. Secara terperici lingkup materi yang terdapat dalam kurikulum KTSP adalah: Makhluk hidup dan proses kehidupannya, yaitu manusia, hewan, tumbuhan dan interaksinya dengan lingkungan serta kesehatan, benda atau materi, sifat-sifat dan kegunaannya meliputi: cair, padat dan gas, energi dan perubahannya meliputi: gaya, bunyi, panas, magnet, listrik, cahaya dam pesawat sederhana, bumi dan alam semesta meliputi: tanah, bumi, tata surya, dan benda-benda langit.

Penelitian tindakan kelas ini dilaksanakan berdasarkan hasil observasi guru kelas $\mathrm{V}$ menganggap bahwa siswanya mampu untuk mencapai nilai 70 untuk mata pelajaran IPA itu sendiri, namun pada kenyataanya masih banyak siswa yang mendapatkan nilai 
hanya mencapai rata-rata saja kurang lebih $30 \%$ sedangkan yang mendapatkan nilai dibawah rata-rata adalah $70 \%$. Selain hasil belajar yang kurang maksimal saya sebagai guru kelas V SDN Prapag Lor 02 dalam proses pembelajarannya lebih sering menggunakan metode yang tradisional saja yaitu metode ceramah dan pemberian tugas. Selain hasil belajar yang kurang maksimal dan metode pembelajaran yang digunakan masih tradisional, kecerdasan yang masih peserta didik tonjolkan hanya 1 atau 2 saja yaitu kecerdasan linguistik dan logika matematika.

Penerapan pendekatan multiple intellegence pada mata pelajaran IPA adalah salah satu bentuk upaya untuk meningkatkan hasil belajar siswa yang sesuai dengan kemampuan yang mereka miliki selain itu juga dapat menghasilkan siswa siswi yang berprestasi. Oleh karena itu, peneliti ingin mencoba merubah metode pembelajaran yang tradisional tersebut menjadi metode pembelajaran yang lebih variatif, kreatif, menyenangkan dan sesuai dengan kecerdasan yang mereka miliki serta sesuai dengan minat dan bakat siswa tersebut. Karena menurut Thomas Amstrong dalam buku pendidikan anak di SD (Hera Lestari Makarsa, 2018: 7.30) mengatakan teori multiple intellegence dapat menjadi pedoman dalam menstrukturkan kurikulum tematik dan pengembangan aktivitas yang dapat mensimulasi ke tujuh intellegence. Esensinya adalah pengajaran harus didasari oleh keinginan untuk mengembangkan kemampuan dibalik intellegence sehingga setiap siswa memiliki peluang berhasil disekolah. Dengan mengembangkan intellegence-intellegencey siswa akan mencadi cerdas dan berhasil dalam setiap pelajarannya.

Menurut Djamarah (2000: 45) "hasil adalah prestasi dari suatu kegiatan yang telah dikerjakan, diciptakan, baik secara individu maupun kelompok". Hasil tidak akan pernah dihasilkan selama orang tidak melakukan sesuatu. Untuk menghasilkan sebuah prestasi dibutuhkan perjuangan dan pengorbanan yang sangat besar. Hanya dengan keuletan, sungguh-sungguh, kemauan yang tinggi dan rasa optimisme dirilah yang mampu untuk mancapainya. Sementara itu, Arikunto (1990: 133) mengatakan bahwa "hasil belajar adalah hasil akhir setelah mengalami proses belajar, perubahan itu tampak dalam perbuatan yang dapat diaamati dan dapat diukur".

Pada dasarnya setiap anak memiliki kedelapan intellegence ( kecedasan bahasa (linguistik), logika-matematika, visual-spasial, kinestetik, musikal, interpersonal, intrapersonal dan naturalis). Hanya saja, sering tidak semuanya terasah dengan baik oleh orang tua, pendidik disekolah, atau sistem pedidikan (kurikulum) Nasional. dengan mengasah intelligence sejak dini, berarti kita memberi anak jalan untuk lebih sukses kelak dikemudian hari.

Setiap individu siswa memiliki derajat kecerdasan yang bervariasi. Tugas guru adalah mengkombinasikan dan memadukan intellegence tersebut ke dalam pembelajaran sehingga mereka dapat belajar sesuai dengan potensi yang mereka miliki. Selain itu dapat menghasilkan siswa-siswi yang berprestasi dan meningkatkan hasil belajarnya.

\section{METODE}

Penelitian ini adalah penelitian tindakan dengan menggunakan pendekatan multiple intellegence. penelitian tindakan kelas adalah penelitian yang dilakukan oleh guru di dalam kelasnya sendiri melalui refleksi diri, dengan tujuan untuk memperbaiki kinerjanya guru, sehingga hasil belajar siswa menjadi meningkat (IGAK Wardani, 2018: 1.15). menurut IGAK Wardani dalam buku penelitian tindakan kelas (2.16) langkahlangkah dalam penelitian tindakan kelas ini terdiri dari empat tahapan dalam satu daur siklusnya yaitu : merencanakan perbaikan, melaksanakan tindakan, mengamati dan melakukan refleksi. Analisis penelitian ini adalah analisis deskriptif kuantitafif kualitatif dimana dalam penelitian ini selain penyajian hasil berupa data maupun angka peneliti juga menentukan bagaimana cara pengolahan hasil penelitian yakni dengan membuat analisisnya dengan menerapkan pendekatan multiple intellegence. Penelitian ini 
dilaksanakan pada peserta didik kelas V SDN Prapag Lor 02 Tahun Pelajaran 2020/2021 selama dua siklus. Siklus I dilaksanakan pada tanggal 10 Agustus 2020. Siklus II dilaksanakan pada tanggal 24 Agustus 2020. Teknik pengumpulan data yang dilakukan dengan observasi dan tes.

\section{HASIL DAN PEMBAHASAN}

Berdasarkan data awal diperoleh pada tes hasil belajar siswa bahwa aktivitas siswa masih dianggap kurang efektif sehingga pembelajaran kurang maksimal. Oleh karena itu penelitian ini berusaha melakukan perbaikan dalam praktik pembelajaran tersebut. Sebagai upaya perbaikan dilakukan dengan penelitian tindakan kelas yang terdiri dari beberapa siklus sampai dengan tujuan pembelajaran yang kita ingin sesuai dengan target siatas KKM yang telah ditentukan. Dalam tindakan ini penelitian menggunakan teknik yang terdiri dari perencanaan, pelaksanaan, observasi, dan refleksi.

Pada tahapan refleksi diadakan analisis data yang diperoleh pada saat pelaksanaan tindakan perbaikan, sehingga diperoleh data apakah target yang ditetapkan telah tuntas atau belum, untuk perbaikan pelaksanaan tindakan yang harus dilakukan beberapa siklus.

Tes hasil belajar merupakan tahap akhir pada kegiatan pembelajaran berlangsung. Dengan adanya tes guru dapat mengetahui sejauh mana kemampuan siswa dalam pembelajaran yang disampaikan oleh guru. Pada bagian ini akan dipaparkan mengenai data hasil perolehan nilai pad pelaksanaan tes hasil belajar siswa pada siklus pertama dalam pelajaran IPA di kelas V SDN Prapag Lor 02 mengenai alat pernapasan manusia. Adapun data diperoleh nilai tersebut adalah sebagai berikut :

Dari ketentuan KKM adalah 70 berdasarkan tes hasil dari siklus pertama yang dilakukan hasilnya sudah mengalami peningkatan dari tes awal. hasil dari tes siklus pertama yang tuntas hanya 15 siswa atau di persentasekan hasilnya adaah $50 \%$ siswa sedangkan sisanya siswa yang belum tuntas adalah 15 siswa atau dipersentasekan adalah 50 \% siswa. Hal ini perlu dilanjutkan pada siklus selanjutnya agar hasil belajar siswa mencapai dari target yang sesuai ketentuan KKM yaitu 70 dengan persentase menjadi $75 \%$ siswa.

Adanya peningkatan dari data awal ke siklus pertama dapat juga dilihat pada grafik berikut ini:

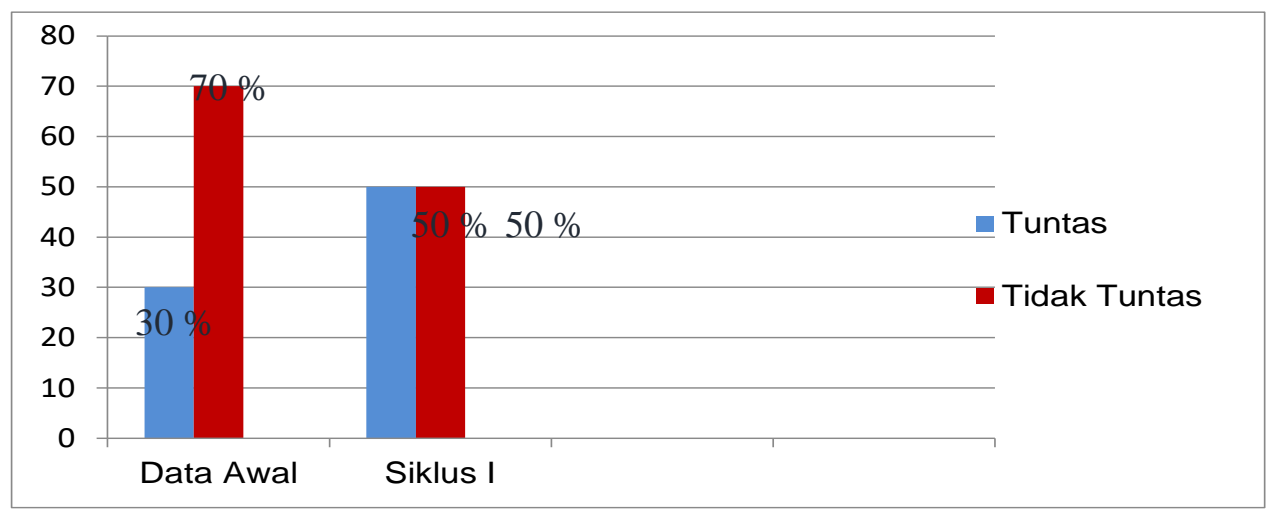

Grafik 1. Data Hasil Belajar Siklus I 
Berdasarkan data grafik 1, siswa yang tuntas pada sklus I yaitu berjumlah 15 siswa atau dipersentasekan $50 \%$ sedangkan yang belum tuntas pada siklus I yaitu 15 siswa atau 50\%. Hasil yang dicapai pada siklus I sudah meningkat dibandingkan dengan data yang diperoleh siswa, namun pada siklus I sudah meningkat hasil belajar siswa tapi belum memenuhi target disamping itu juga pembelajaran yang disampaikan oleh guru belum dipahami oleh siswa secara baik dan pengolahan pembelajaran tidak sesuai dengan alokasi waktu dan RPP. Perencanaan tindakan unuk proses perbaikan data awal dan siklus I bertujuan untuk meningkatkan pembelajaran yang meliputi aktivitas guru dan siswa sehingga hasil belajar meningkat pada siklus II.

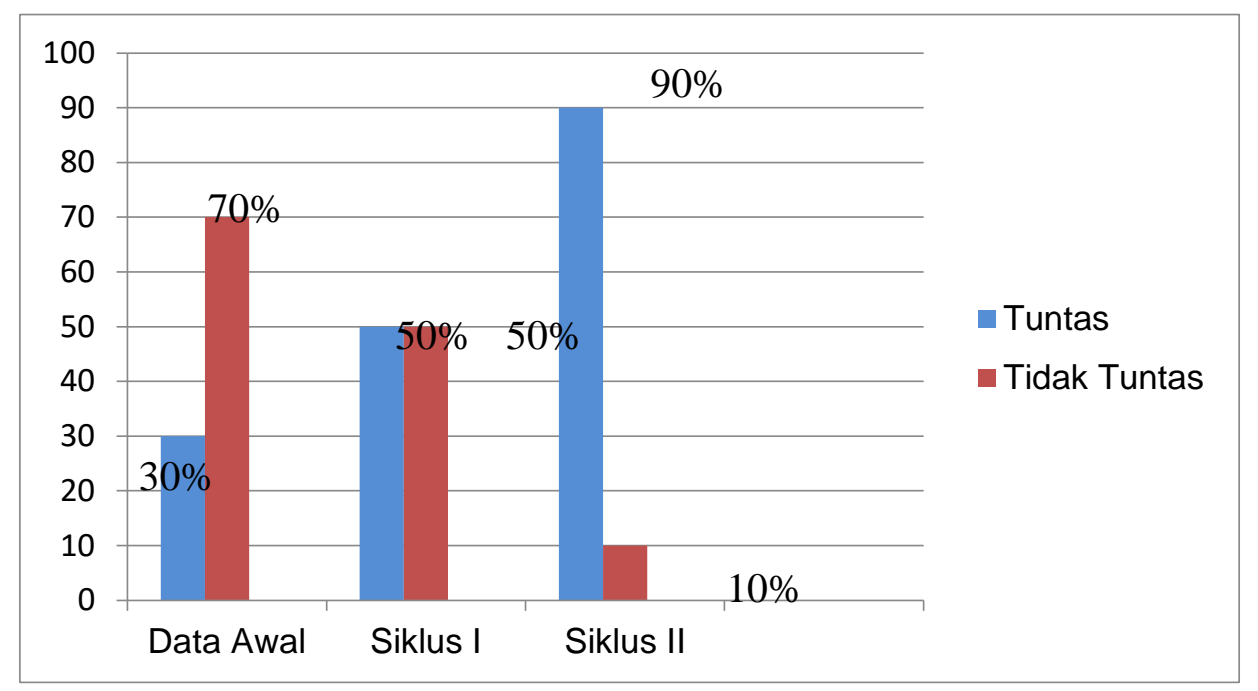

\section{Grafik 2. Data Hasil Belajar Siswa Siklus II}

Dari ketentuan KKM adalah 70 berdasarkan tes hasil dari siklus II yang dilakukan hasilnya sudah mengalami peningkatan dari tes siklus I. Hasil dari tes siklus II yang tuntas 27 siswa atau di persentasekan hasilnya adalah $90 \%$ siswa, sedangkan sisanya siswa yang belum tuntas adalah 3 siswa atau dipersentasekan adalah $10 \%$. Maka dinyatakan bahwa penggunaan pendekatan multiple intellegence dapat meningkatkan hasil belajar siswa.

Berdasarkan hasil analisis tes hasil belajar yang selama dua siklus berlangsung ini menyimpulkan bahwa pembelajaran IPA materi alat pernapasan manusia dengan menggunakan pendekatan multiple intellegence ini dapat menigkatkan hasil belajar siswa, minat belajar dan penggunaan model yang baik diterapkan di SD hal ini ditunjukkan hasil penelitian dari mulai data awal atau prasiklus, siklus I dan siklus II adalah sebagai berikut: Data awal mendapat 9 siswa yang mencapai KKM atau sudah tuntas maka dipersentasekan menjadi $30 \%$ sedangkan sisanya yang mendapat nilai tidak tuntas yaitu 21 siswa atau dengan persentase $70 \%$.

Pada siklus I mendapatkan nilai tes hail belajar yang mendapat nilai tuntas yaitu 15 siswa dengan persentase $50 \%$ sedangkan sisanya yang tidak tuntas mendapat nilai 15 siswa dengan persentase $50 \%$ namun pada siklus II mengalami peningkatan hasil belajar yang mencapai diatas prosentasi $75 \%$ dengan persentase $90 \%$ sedangkan sisanya yang tidak tuntas 3 siswa dengan persentase $10 \%$.

Thomas Amstrong dalam buku pendidikan anak di SD (Hera Lestari Makarsa, 2018: 7.30) mengatakan teori multiple intellegence dapat menjadi pedoman dalam 
menstrukturkan kurikulum tematik dan pengembangan aktivitas yang dapat mensimulasi ke tujuh intellegence. Esensinya adalah pengajaran harus didasari oleh keinginan untuk mengembangkan kemampuan dibalik intellegence sehingga setiap siswa memiliki peluang berhasil disekolah. Dengan mengembangkan intellegenceintellegencey siswa akan mencadi cerdas dan berhasil dalam setiap pelajarannya. Sejalan dengan Undang-undang Pendidikan Nasional Nomor 20 Tahun 2003 tentang sistem pendidikan nasional pasal 1 ayat 1 yang menjelaskan bahwa Pendidikan adalah usaha sadar dan terencana untuk mewujudkan suasana belajar dan proses pembelajaran agar peserta didik secara aktif mengembangkan potensi dirinya untuk memiliki kekuatan spiritual keagamaan, pengendalian diri, kepribadian, kecerdasan, akhlak mulia, serta keterampilan yang diperlukan dirinya, masyarakat, bangsa dan negara.

\section{SIMPUL AN}

Berdasarkan hasil penelitian yang dilakukan dengan menggunakan pendekatan multiple intellegence ini pada peserta didik kelas V SDN Prapag Lor 02, materi alat pernapasan manusia dapat menunjukkan hasil yang maksimal dan siswa dalam pembelajarannya lebih efektif, semangat dan menyenangkan. Selain itu Pendekatan ini juga dapat memicu kecerdasan-kecerdasan yang awalnya hanya satu kecerdasan yang mereka gunakan setelah menggunakan pendekatan ini siswa dapat menggunakan kecerdasan yang lainnya. Sehingga hasil belajar yang mereka dapat meningkat. Adapun kecerdasan multiple intellegence ini meliputi kecerdasan Kecerdasan bahasa, Kecerdasan Logika - Matematika, Kecerdasan Visual - Spasial, Kecerdasan Musikal, Kecerdasan Kinestetik Tubuh, Kecerdasan Interpersonal, Kecerdasan Intrapersonal dan Kecerdasan Naturalis.

\section{DAFTAR PUSTAKA}

Andriani, Durri. Dkk. (2018). Metode Penelitian. Jakarta: Universitas Terbuka.

Anggoro, M. Toha. Dkk. (2018). Metode Penelitian. Jakarta: Universitas Terbuka

Dilaga, Nur. (2014). Meningkatkan Hasil Belajar IPA Melalui Strategi Pembelajaran

Berbasis Multiple intellegence Pada Siswa Kelas IV SD Negri Gembongan. Gembongan: Universitas Negeri Yogyakarta.

Hamdani, Drs., MA. (2011). Strategi Belajar Mengajar. Bandung: CV Pustaka Setia

Hanikah. (2013). modul belajar dan pembelajaran. Cirebon: universitas muhammadiyah Cirebon.

Indonesia, Kementerian Pendidikan dan Kebudayaan. (2018). Buku Guru Kelas 5 Tema 2 Kurikulum 2013. Jakarta : Kementerian Pendidikan dan Kebudayaan

Indonesia, Kementerian Pendidikan dan Kebudayaan. 2018. Buku Tematik Terpadu kelas 5 Tema 2 Kurikulum 2013. Jakarta : Kementerian Pendidikan dan Kebudayaan

Rustaman, Nuryani. (2018). Materi dan Pembelajara IPA SD. Tanggerang Selatan: Universitas Terbuka.

Sutarno, Nano. Dkk. (2018). Materi Pokok Materi Pembelajaran IPA SD. Jakarta: Universitas Terbuka

Taufiq, Agus. (2011). Materi Pokok Pendidikan Anak di SD. Jakarta: Universitas Terbuka.

Safitri. (2013). Pengaruh Pendekatan Multiple intellegences Melalui Metode Pembelajaran Langsung Terhadap Sikap dan Hasil Belajar Kimia Peserta Didik di SMA Negeri Tellu Limpoe. Makasar: Universitas Negeri Makasar. 
Sujiono, Yuliani Nurani, dkk. (2018). Materi Pokok Metode Pengembangan Kognitif. Jakarta: Universitas Terbuka.

Taufiq, Agus. (2018). Materi Pokok Pendidikan Anak di SD. Jakarta: Universitas Terbuka.

Wardani, IGAK dan Wihardit, Kuswaya. (2018). Materi penelitian tindakan kelas. Jakarta: Universitas Terbuka.

Winataputra, Udin S.dkk. (2018). Teori belajar dan pembelajaran. Jakarta: Universitas Terbuka. 